\title{
A missão italiana
}

The Italian mission

Edelcio Mostaço

Edelcio Mostaço

Professor do Departamento de Artes Cênicas e do PPGT da UDESC

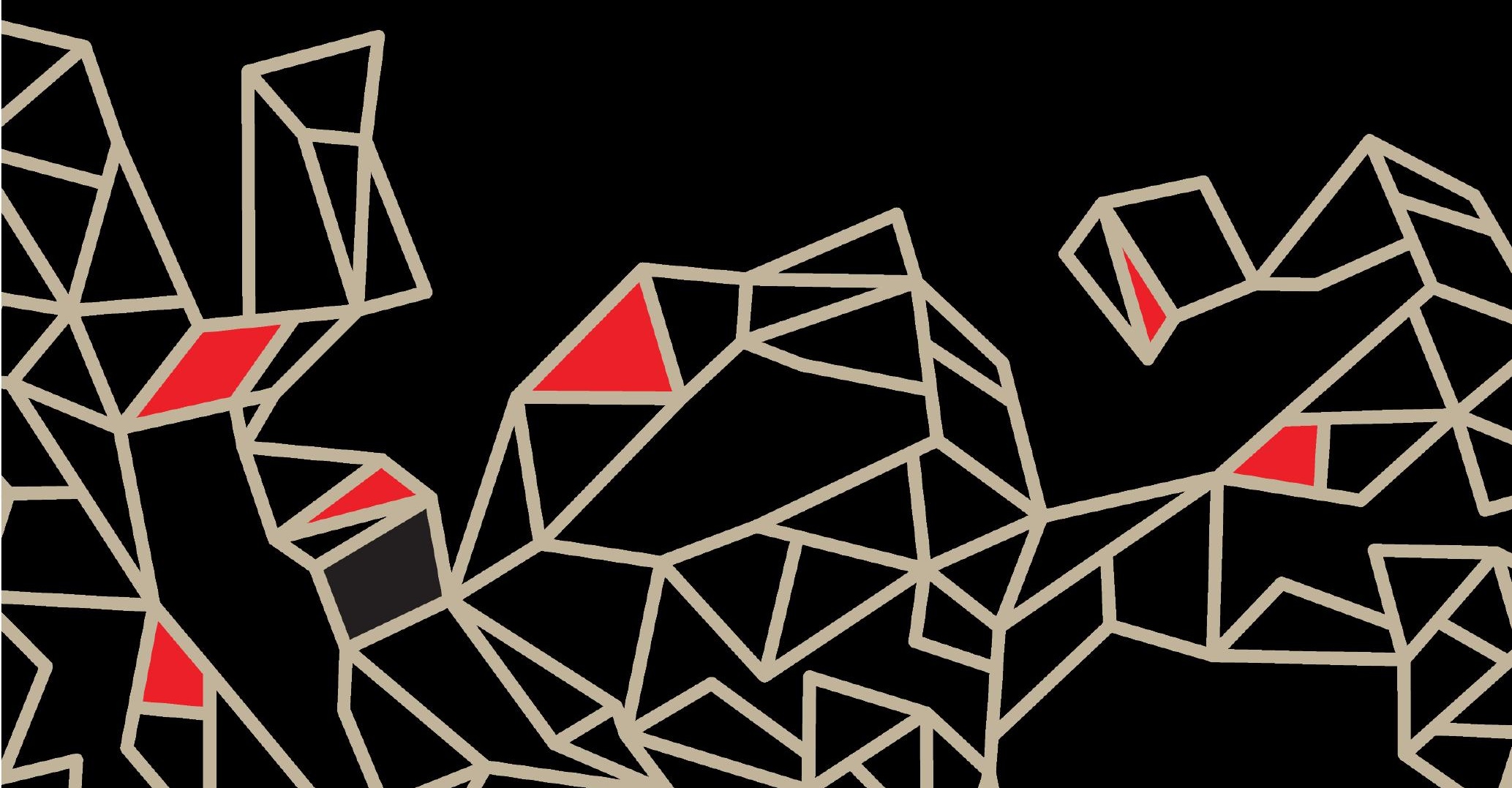




\section{Resumo}

Esta resenha enfoca o livro A missão italiana, de Alessandra Vanucci, dedicado a situar a presença dos diretores italianos no Teatro Brasileiro de Comédia (TBC) e no teatro brasileiro entre as décadas de 1950 e 1960. Além disso, mostra a formação do Grupo dos Onze na Roma ainda ocupada pelos nazistas e suas primeiras atuações profissionais. A autora desenvolve renovadas estratégias analíticas e derruba alguns mitos ainda persistentes em nossa historiografia.

Palavras-chave: teatro brasileiro, TBC, diretores.

\section{Abstract}

This review focuses on the book The Italian Mission, by Alessandra Vanucci, which analyses the Italian directors that worked within the Teatro Brasileiro de Comédia (TBC) and in the Brazilian theatre between the 1950s and the 1960s. It emphasizes the constitution of the Group of Eleven in Rome, still occupied by Nazi forces, and their early professional activities. The author develops new research strategies and argues against some analytical myth among our historians.

Keywords: Brazilian theatre, TBC, theatrical directors.

A obra de Alessandra Vanucci foca a presença e a atuação de cinco encenadores italianos que se alternaram ou se sucederam à frente do Teatro Brasileiro de Comédia (TBC), casa fundada em 1948 em São Paulo e responsável pela consolidação da renovação cênica no país.

O texto não se constitui numa historiografia convencional. Além de situar as circunstâncias de vida de cada qual, remete, sempre que necessário, a fatos históricos e circunstanciais, situando com propriedade ao menos duas décadas do intrépido passado recente do Brasil. Adolfo Celi, Ruggero Jacobbi, Luciano Salce, Flaminio Bollini Cerri e Gianni Ratto são as destacadas figuras dessa inebriante incursão, que, muito além de mero deslocamento intercontinental, configurou verdadeira e acidentada desterritorialização sociocultural. Muito jovens, deixaram para trás uma Itália devastada pela guerra 
para se embrenhar num trópico que, em suas imaginações, era povoado por negros e animais em desfile pelas ruas das metrópoles. Meses antes, outro italiano lunático havia fundado a empresa cênica, num gesto de amor à arte, interessado também em torná-la lucrativa, apostando no incipiente mercado cultural. Tendo como respaldo gerencial um estágio realizado em Chicago e a bem-sucedida direção da corporação de indústrias pertencentes à família Matarazzo, Franco Zampari convidou Adolfo Celi a vir dirigir a nova casa que acabara de fundar.

De passagem pela Argentina, terminando uma filmagem, Celi decidiu verificar in loco se era mesmo verdade o que o outro the prometia por telefone. Encontrou um belo teatro primorosamente montado, ocupando quatro andares de um edifício reformado e tornado, desde então, o mais novo espaço cênico da pujante urbe que crescia vertiginosamente. Seus olhos brilharam ao ver o conjunto arquitetônico e as simpáticas atrizes - amadoras - que compunham o elenco, que o aguardavam como mestre e futuro condutor nos meandros da arte. A única já profissionalizada era Cacilda Becker, um feixe de músculos e nervos talhados para a cena.

Essas são algumas das saborosas histórias contadas. Com A missão italiana, temos a introdução de novas angulações para surpreender o debate historiográfico brasileiro. Vanucci possui dupla cidadania e se exprime com desenvoltura nos dois idiomas, além de deter incansável paciência para revirar baús e guardados, o que a torna uma respeitada pesquisadora lá e cá, em função de suas diversas publicações.

O olhar estrangeiro algumas vezes nos causa estranheza, pois nem sempre nos reconhecemos na cena desenhada. Aqui, contudo, ele se torna revelador e, mais que isso, inovador, por introduzir angulações ainda pouco exploradas em nossas narrativas históricas. Ao invés de discutir o moderno enquanto marco, Vanucci detém-se sobre o processo de nossa modernização cênica, em que Adolfo Celi, Ruggero Jacobbi, Luciano Salce, Flamínio Bollini Cerri e Gianni Ratto constituíram, mais que meros personagens, verdadeiros articuladores. Por esse motivo, a missão, seja em sua sinonímia jesuítica ou francesa, deve ser tomada como fina ironia argumentativa.

O texto nasceu de uma extensa pesquisa nos dois continentes e de diversas entrevistas, revolvendo bibliotecas e arquivos, particulares e públicos, além de perquirir a totalidade dos textos redigidos pelos missioneiros. De todos eles, sem dúvida foi Jacobbi quem mais escreveu, legando importantes 
anotações ensaísticas e críticas, sempre com afiada inteligência e refinado perfume, todo próprio. O grupo chegou a formar, na Roma ainda invadida pelos alemães na Segunda Guerra, o Grupo dos Onze, organizando um colóquio em que eram debatidas ideias e redigido, a múltiplas mãos, um nada modesto diário denominado $A$ educação teatral. De algum modo, todos estiveram ligados à Accademia d'Arte Drammatica de Roma, fundada por Silvio D'Amico, uma escola de teatro e cinema por ele supervisionada, a duras penas, para impedir que em seus corredores circulassem as cogitações fascistas. A figura do diretor teatral era central naquela instituição, considerada um marco para o estabelecimento de um teatro de arte, que fazia do respeito ao texto uma norma derivada dos ensinamentos de Copeau, especialmente enquanto fator educativo de gosto junto às plateias.

A começar por Adolfo Celi, o primeiro contratado pelo TBC, os demais foram sendo chamados, um a um, para se associar ao empreendimento. $\mathrm{O}$ último deles, Alberto D’Aversa, dez anos mais jovem que os partícipes dos Onze, não teve sua trajetória rastreada na obra. Zampari e Celi foram os idealizadores do projeto cultural da casa de espetáculos com elenco fixo, rígido regime de alternância nos papéis centrais, absoluta dedicação ao ofício e, sobretudo, respeito à encenação, tudo aquilo que as demais companhias do período - especialmente as cariocas - não cultivavam, pois ainda estavam enredadas, em sua grande maioria, num sistema estelar modelado pelas práticas lusitanas decididamente arcaico.

O repertório foi cuidadosamente delineado para permitir ao elenco migrar do semiamadorismo para as criações psicologicamente mais densas. Diversos estilos e épocas se alternaram sobre o palco, como uma schilleriana propedêutica de formação de público, planejada para fazer o projeto deslanchar sem sobressaltos. Entusiasmado com os sucessos iniciais que o público absorvia como realizações coetâneas com as de Paris ou Nova York, Zampari em seguida fundou a Vera Cruz, empreendimento destinado a produzir cinema, na tentativa de açambarcar o mercado do entretenimento. Nem tudo correu como esperado.

As brigas internas nos bastidores, as acidentadas filmagens de Caiçara, primeiro longa metragem dirigido por Celi, e, em seguida, o desastrado Floradas na serra, com suas trapalhadas administrativas e de produção, contam entre os fatores que, ao cabo de cinco anos, levaram o projeto teatral a ser revisto e mudar de rumo. Treze à mesa, de Sauvajon, foi a primeira concessão, 
montagem dirigida por Jacobbi para equilibrar a bilheteria; o zigue-zague se prolonga até 1960, quando Zampari abandona seu posto, transformando o TBC numa experiência artística não muito distante da realidade teatral circundante. Em seu texto, Vanucci situa tais alternâncias sob o epíteto de transição necessária, expressão cunhada por Jacobbi para marcar a oscilação entre o conhecido e o desconhecido, o novo e o velho, o teatro de direção e aquele de ator, em que as ideias de trânsito e vacilação balizavam as facetas da necessidade, entendida em sentido hegeliano (alma filosófica/alma comercial). Ou seja, não se transita aqui por um território liso, mas escarpado, onde rizomas se espalham e se estiolam, nem todos alcançando a plenitude do devir.

Assim, a autora desloca as estratégias analíticas que ainda percebem o fluxo histórico em franco compromisso com as vanguardas (que insistem em tomar tais movimentos como rupturas, avanços e recuos, mortes e ressurreições), em benefício de novos perceptos embebidos por outras potências e devires. É também o que a leva a rejeitar o postulado das ideias fora do lugar, caro a certas analíticas de esquerda, para ressaltar o que aqui foi produzido enquanto transculturação, em que não é o passado (ou a cultura) que veio civilizar (ou modernizar) o trópico, mas, ao contrário, nele injetar nova energia de desenvolvimento, acertando o horário mundial através da viagem: "uma transculturação imperfeita, anômala, um lance viajante que se reorganiza a cada etapa, transitando por lugares e tradições, sendo assimilada/negada/ antropofagizada e garantindo sua organicidade pela vivência de artistas e intelectuais viajantes que a veiculam" (p. 298).

A missão italiana deriva, portanto, de uma antonomásia: aquele vínculo placentário que se incumbiu de nutrir, entre Brasil e Europa, instrumentos expressivos comuns. Não há dependência estrutural entre os territórios, mas legítima intercomunicação, "participação e contribuição a um universo cultural ao qual pertencemos que transborda as nações e os continentes, permitindo a reversibilidade das experiências e a circulação dos valores” (p. 299).

Durante muito tempo e por variadas vozes, os italianos do TBC foram acusados de ter promovido uma elitização do nosso teatro, de ter aberto um fosso em sua calçada, isolando-o das tradições da cena nacional. O primeiro deles foi o crítico Miroel Silveira, fiel defensor da primazia do polonês Ziembinski no plano da direção e de atores tocados pelo espírito de renovação, como Dulcina, Itália Fausta ou mesmo Procópio Ferreira. Em seguida, pelo Teatro de Arena, cuja virada nacionalista implicou alardear que não usava 
black-tie, que nada tinha de burguês e queria entronizar o operário como personagem central na cena. Todos aqueles que operam no primeiro ou no segundo raciocínios esquecem que foi Ruggero Jacobbi o mentor intelectual do TPE - grupo estudantil ligado ao Partido Comunista e associado, desde 1956, ao Arena -, que viabilizou o aparecimento de Black-Tie. Esquecem também que ele foi professor na EAD e o fundador, em 1958, do curso de arte dramática da Universidade do Rio Grande do Sul, responsável pela formação, dentre outros, de Fernando Peixoto, Antônio Abujamra e Luiz Carlos Maciel. Todos jovens - os garotos, como alude - por ele insuflados, e responsáveis pela enorme mudança de paradigmas que o teatro brasileiro conhecerá após os anos 1960.

Tal virada nacionalista, na maior parte das considerações conotada tão somente em sua dimensão política nacionalista, inerente à oposição anti-imperialista (tese sustentada, desde 1958, pelo Partido Comunista Brasileiro), necessita ser redimensionada naquilo que possui de cultural, deixando falarem menos o viés róseo que a coloriu na Independência e o vermelho que a tingiu ao final dos anos 1950. Muitos historiadores do teatro brasileiro não ultrapassaram ainda tais limites e contingências. Nos argumentos de Vanucci, tal enfoque conhece outra interpretação, ainda uma vez estribada em Jacobbi:

[...] sua reorientação da história da cultura como história das ideias, não sequestrável por obsoletas categorias de influências e pondo em questão o paradigma nacionalista, contém uma sugestiva indicação metodológica. Será o conceito de nação, embutido no nacionalismo, com seus equívocos corolários de dependência, atraso e, finalmente, nacionalização de ideias, categoria côngrua para a história das artes, especialmente no caso do teatro, arte viajante por excelência já que seus artistas viajam necessariamente com ela? (p. 300).

Com o TBC e sua missão italiana, uma irreversível mudança de foco de atenção registrou-se no território da cena brasileira: do Rio de Janeiro para São Paulo. $O$ fato não é apenas geopolítico e interessa menos em seus aspectos explicitamente cênicos, mas principalmente os culturais como um todo, quando se verificam outras iniciativas na área (a Bienal, o MASP, a Vera Cruz, a TV Tupi etc.) adquirirem primazia e projeção na cultura nacional. Estruturada com uma massiva leva de italianos imigrados desde cem anos antes, a cidade foi absorvendo seus hábitos e presença, a ponto de levar Lélia Abramo, uma legítima oriundi, a declarar "que a cidade recebera por herança 
os hábitos de "padaria, confraria e palco"' (p. 304). Arrisco a afirmar que, por debaixo de tal declaração, outra dimensão histórica possa ser vislumbrada, estribada na tradição legada pelos filodramáticos e anarquistas que instilaram na cidade o gosto popular pelo teatro, preparando assim, por décadas, uma afinidade eletiva. Isso pode explicar, como hipótese, a refração carioca à renovação e sua mais bem apreciada mudança de foco para a cidade bandeirante, açulada por mais ampla e decisiva modernização de ideias e instituições. Destarte, o TBC só poderia ter florescido em São Paulo, onde as noções de planejamento, direção, conjunto e eficiência se plasmavam bem mais aclimatadas que nas lânguidas e ensolaradas praias cariocas.

Como bem se conhece, o TBC encontrou não poucas resistências perante o público e a crítica do Rio de Janeiro, que também conheceu uma evasão de seus artistas rumo a São Paulo. Num primeiro momento, a renovação foi implacável para com aqueles que insistiam em ensaiar com uma cadeira no palco.

Após esse surto renovador, todavia, Vanucci é perspicaz ao anotar que, com as sucessivas saídas de estrelas do TBC para fundarem suas próprias companhias, estas passam a exibir seus codinomes artísticos como fator de marketing, na antiquada mentalidade de promoção à base de uma estrela puxando o conjunto. Ou seja, a onda renovadora entra em perigeu a partir da segunda metade da década de 1950, embora certas conquistas artísticas e morais diante do palco estivessem já consolidadas - a direção era um princípio basal e todas as estrelas insurgentes buscaram entre os italianos aqueles disponíveis para dirigi-las. Entramos, assim, no refluxo da maré.

\section{Referências bibliográficas}

VANUCCI, A. A missão italiana: histórias de uma geração de diretores italianos no Brasil. São Paulo: Perspectiva, 2014.

Recebido em 08/04/2015

Aprovado em 23/05/2015

Publicado em 30/06/2015 